This mutation was identified with renal dysfunction in all six affected patients in a dominant way of inheritance over three generations and was never observed in 100 control chromosomes.

Our study represents the first Italian molecular characterization of a MODY-5 family and further confirm that mutations in $H N F-1 \beta$ gene are associated with a syndrome characterized by MODY and kidney disease.

The presence of this splice site $H N F-1 \beta$ mutation support previously reported results [3], suggesting that alterations in the conserved sequence elements at the splice donor site of intron 2 might be a hot spot region for mutations in the $H N F-1 \beta$ gene.

Acknowledgements. This work was supported by grants from the Italian Ministry of Health (Ricerca Corrente - G.Gaslini Institute, 1999) and Telethon-Italy 1999.

I. Carbone, M. Cotellessa, C. Barella, C. Minetti, G. M. Ghiggeri, G. Caridi, F. Perfumo, R. Lorini

\section{Identification of a gain-of-function mutation in the HNF-1及 gene in a Japanese family with MODY}

To the Editor: Mutations in the hepatocyte nuclear factor $(H N F)-1 \beta$ gene cause maturity-onset diabetes of the young (MODY5) [1]. Clinical examinations of patients with the mutations have shown MODY5 to be associated with progressive renal dysfunction and bilateral renal cysts as well. Three of the seven mutations so far reported have been identified in Japanese [1-6]. In order to ascertain the prevalence of $H N F$ $1 \beta$ mutations in early-onset Type II (non-insulin-dependent) diabetes mellitus in Japanese more precisely, we screened a larger group of 111 Japanese patients with early-onset Type II diabetes for mutations in the $H N F-1 \beta$ gene. Ten of the patients were classified as having MODY, with Type II diabetes in at least three generations consistent with autosomal dominant transmission and onset of the disease in patients before 25 years of age. The study group also includes 85 non-obese $\left(\mathrm{BMI}<25 \mathrm{~kg} / \mathrm{m}^{2}\right)$ patients with Type II diabetes diagnosed before 15 years of age because our previous study of MODY3 in young Japanese patients suggested that many of these patients have a monogenic form of diabetes [7]. The other sixteen patients were diagnosed with diabetes before 35 years of age and had a family history of diabetes among first-degree relatives. The minimal promoter, coding regions and flanking introns of the $H N F-1 \beta$ gene were directly sequenced in these patients, resulting in the identification of a novel missense mutation (TCC to TTC: S36F) in the heterozygous state in one MODY family. The serine residue at codon 36 is conserved in human, mouse, and rat $H N F-1 \beta$. This nucleotide alteration was not found in any of the 100 Japanese control subjects (200 alleles).

The subject with the S36F mutation is a 46-year-old female who was diagnosed with Type II diabetes at 17 years of age. She also has proteinuria and two cysts (diameter; $6.9 \mathrm{~cm}$ and $8.9 \mathrm{~cm}$ ) in the left kidney. Her serum creatinine concentration is normal $(0.6 \mathrm{mg} / \mathrm{dl}$; normal 0.6 to $1.0 \mathrm{mg} / \mathrm{dl})$ at present. Genotyping of other family members with diabetes was done (Fig. 1A). The mutation was found in the subject's elder daughter who was diagnosed with Type II diabetes at 14 years

\section{References}

1. Horikawa Y, Iwasaki N, Hara M et al. (1997) Mutation in hepatocyte nuclear factor- $1 \beta$ gene (TCF2) associated with MODY. Nat Genet 17: 384-385

2. Nishigori H, Yamada S, Kohama T et al. (1998) Frameshift mutation, A263fsinsGG, in the hepatocyte nuclear factor$1 \beta$ gene associated with diabetes and renal dysfunction. Diabetes 47: 1354-1355

3. Iwasaki N, Okabe I, Momoi MY, Ohashi H, Ogata M, Iwamoto Y (2001) Splice site mutation in the hepatocyte nuclear factor- $1 \beta$ gene, IVSnt $+1 \mathrm{G}>\mathrm{A}$, associated with maturity-onset diabetes of the young, renal dyplasia and bicornuate uterus. Diabetologia 44: 387-391

4. Weng JP, Lehto M, Forsblom C, Huang X, Li H, Groop LC (2000) Hepatocyte nuclear factor- $1 \beta$ (MODY-5) gene mutations in Scandinavian families with early-onset diabetes or kidney disease or both. Diabetologia 43: 131-132

Corresponding author: R. Lorini ( $\bowtie)$ Department of Pediatrics, University of Genova, G. Gaslini Institute, Italy

of age $(\mathrm{BMI}=22.9)$ and is being treated with insulin. The same mutation was also present in the 68-year-old mother, who was diagnosed with Type II diabetes around 60 years of age. However, interestingly, the S36F mutation was not identified in the other 17-year-old daughter $(\mathrm{BMI}=20.3)$, whose glycosuria was noticed at 11 years of age by an annual health examination, suggesting that other diabetogenic factors contributed to the development of diabetes in this subject.

In order to determine whether the mutation identified in this family alters the function of the HNF- $1 \beta$ protein, the effect of the wild-type and mutant $H N F-1 \beta$ on transcription from three different promoters of the target genes was examined. HeLa cells were transfected with $500 \mathrm{ng}$ of pcDNA3.1-wild type (WT)-HNF-1 $\beta$ or pcDNA3.1-S36F-HNF-1 $\beta$ expression vector with L-type pyruvate kinase (PKL) and transthyretin (TTR) promoter luciferase reporter genes (Fig.1B). The transactivation ability of S36F-HNF-1 $\beta$ was significantly increased by $45.3 \%$ (PKL: $p=0.028$ ) and by $56.7 \%$ (TTR: $p=0.022$ ) compared with WT-HNF-1 $\beta$. The HNF-1 $\beta$ up-regulates GLUT2 gene expression in mouse insulin-secreting MIN6 cells [2]. A significant increase in the transactivation activity of S36F-HNF-1 $\beta$ compared with WT-HNF-1 $\beta$ also was observed in these cells $(p=0.005)$. S36F-HNF-1 $\beta$ (25-1000 ng) consistently showed $12-57 \%$ higher activity on TTR and GLUT2 reporters compared WT-HNF-1 $\beta$ and the activity was significantly increased at high concentrations (100 ng- $1 \mu \mathrm{g}$ ). These results suggest that $\mathrm{S} 36 \mathrm{~F}$ is a gain-of-function mutation. We previously reported that $\mathrm{HNF}-1 \beta$ mutations impair pancreatic beta-cell function by loss-of-function and dominant-negative mechanisms [2]. Gain-of-function could be a third mechanism, although its pathogenesis of impaired insulin secretion is not known. Recently, it has been reported that a frameshift mutation (P328L329fsdelCCTCT), identified in a European MODY5 family with renal abnormalities, acts as a gain-of-function mutation ( twofold) [8]. Thus, S36F mutation in the $H N F-1 \beta$ gene might affect the clinical phenotypes in this MODY family.

In conclusion, we have identified a novel missense mutation in the $H N F-1 \beta$ gene in a Japanese family with MODY but the significance of the mutation in the development of diabetes in the family is not clear. The present results together with previous ones $(1,2,6$ and this study) indicate that $H N F$ - 


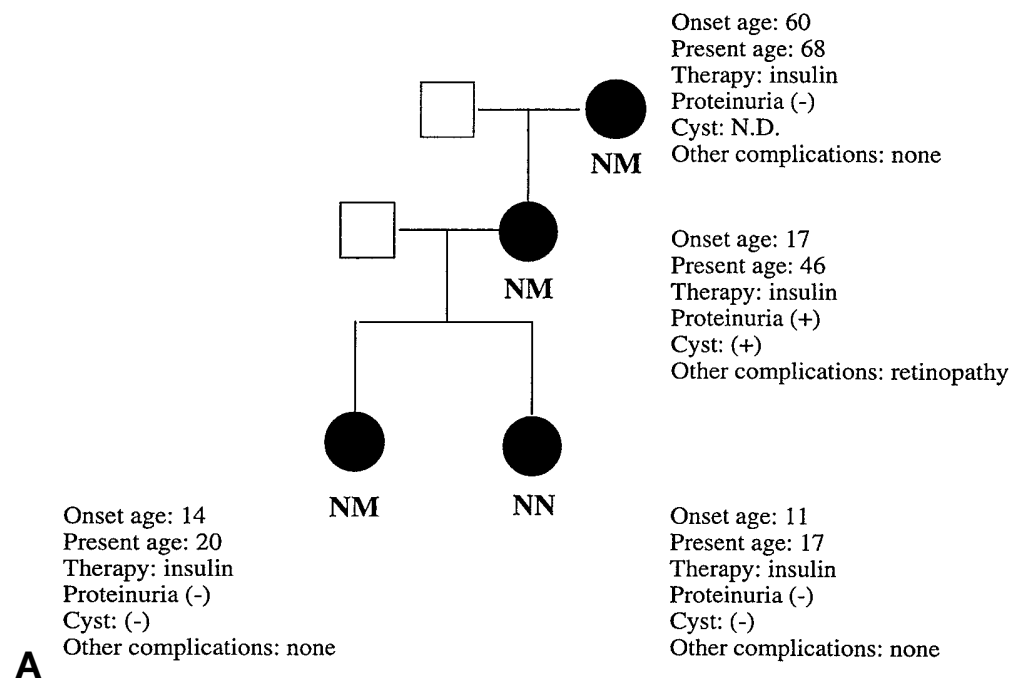

PK-L (HeLa)

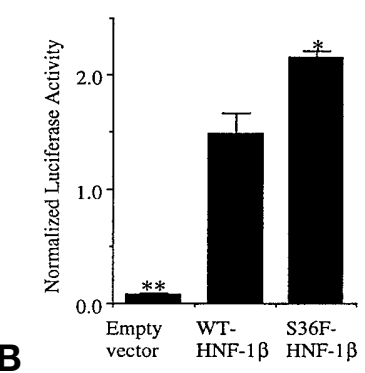

TTR (HeLa)

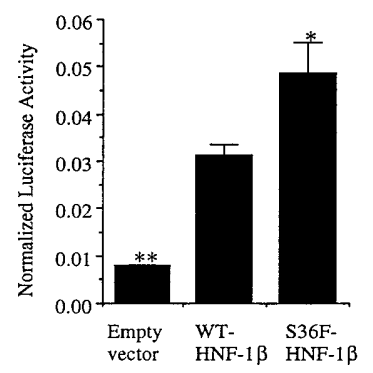

GLUT2 (MIN6)

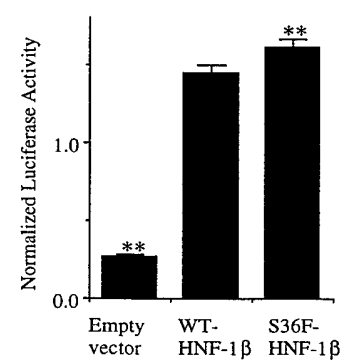

Fig.1. A The family with $\mathrm{S} 36 \mathrm{~F}-H N F-1 \beta$ mutation. Subjects with diabetes are denoted by filled symbols, and non-diabetic subjects by open symbols. Genotype: N, normal; M, mutation. Clinical information (onset age, present age, therapy, complications) is shown. N.D., not determined. B Transactivation activities of wild-type (WT) and S36F-HNF-1 $\beta$. HeLa or MIN6 cells were transfected with $0.5 \mu \mathrm{g}$ of pcDNA3.1-HNF- $1 \beta$ expression constructs and $0.5 \mu \mathrm{g}$ of the reporter genes together with $10 \mathrm{ng}$ of pRL-SV40 internal control vector. Luciferase activity was measured after $48 \mathrm{~h}$ and normalized by the activity of pRL-SV40 (Promega, Tokyo, Japan). The results were from three independent experiments; means $\pm \mathrm{SEM}$, ${ }^{*} p<0.05,{ }^{* *} p<0.01$ compared with WT-HNF-1 $\beta$

$1 \beta$ mutations are not a major cause [prevalence, $\sim 1.9 \%(\sim 4 /$ 208)] of MODY or early-onset Type II diabetes in Japanese.

Acknowledgements. This work was supported by grants from the Japanese Ministry of Education, Culture, Sports, Science and Technology, Japan Diabetes Foundation and Research for the Future Program of The Japan Society for the Promotion of Science (97L00801).

I. Yoshiuchi, K. Yamagata, Q.Zhu, I.Tamada, Y.Takahashi, K. Onigata, J. Takeda, J. Miyagawa, Y. Matsuzawa

\section{References}

1. Horikawa Y, Iwasaki N, Hara M et al. (1997) Mutations in hepatocyte nuclear factor $1 \beta$ gene (TCF2) associated with MODY. Nat Genet 17: $384-385$
2. Tomura H, NishigoriH, Sho K, Yamagata K, Inoue I, Takeda J (1999) Loss-of-function and dominant-negative mechanisms associated with hepatocyte nuclear factor- $1 \beta$ mutations in familial type 2 diabetes mellitus. J Biol Chem 274: 12975-12978

3. Lindner TH, Njlstad PR, Horikawa Y, Bostad L, Bell GI, Sovik O (1999) A novel syndrome of diabetes mellitus, renal dysfunction and genital malformation associated with a partial deletion of the pseudo-POU domain of hepatocyte nuclear factor- $1 \beta$. Hum Mol Genet 8: 2001-2008

4. Bingham C, Ellard S, Allen L et al. (2000) Abnormal nephron development associated with a frameshift mutation in the transcription factor hepatocyte nuclear factor- $1 \beta$. Kidney Int 57: 898-907

5. Bingham C, Bulman MP, Ellard S et al. (2001) Mutations in the hepatocyte nuclear factor- $1 \beta$ gene are associated with familial hypoplastic glomerulocystic kidney disease. Am J Hum Genet 68: 219-224

6. Iwasaki N, Okabe I, Momoi MY, Ohashi H, Ogata M, Iwamoto Y (2001) Splice site mutation in the hepatocyte nuclear factor- $1 \beta$ gene, IVS2nt $+1 \mathrm{G}>\mathrm{A}$, associated with maturity-onset diabetes of the young, renal dysplasia and bicornuate uterus. Diabetologia 44: 387-391

7. Yamada S, Tomura H, Nishigori H et al. (1999) Identification of mutations in the hepatocyte nuclear factor- $1 \alpha$ gene in Japanese subjects with early-onset NIDDM and functional analysis of the mutant proteins. Diabetes 48: 645-648

8. Wild W, von Strandmann EP, Nastos A et al. (2000) The mutated human gene encoding hepatocyte nuclear factor $1 \beta$ inhibits kidney formation in developing Xenopus embryos. Proc Natl Acad Sci USA 97: 4695-4700

Corresponding author: K. Yamagata, Department of Internal Medicine and Molecular Science, Graduate School of Medicine, B5, Osaka University, 2-2 Yamada-oka, Suita, Osaka 565-0871, Japan, e-mail: kazu@imed2.med.osaka-u.ac.jp 